\title{
DISTÚRBIOS METABÓLICOS POR MANEJO ALIMENTAR INADEQUADO EM RUMINANTES: NOVOS CONCEITOS
}

\author{
DESÓRDENES METABÓLICOS POR MANEJO NUTRICIONAL INADECUADO EN \\ RUMIANTES: NUEVOS CONCEPTOS
}

METABOLIC DISORDERS DUE TO IMPROPER HANDLING OF NUTRITION IN

RUMINANTS: NEW CONCEPTS

VAN CLEEF, H. ERIC ${ }^{1}$ M.Sc, PATIÑO, P. RENÉ ${ }^{2}$ Dr, NEIVA JR, P. ARNALDO ${ }^{3}$ Dr, SERAFIM, S. RENATA ${ }^{4}$ Dr, REGO, C. ANIBAL ${ }^{5}$ M.Sc, GONÇALVES, S. JOSEMIR ${ }^{6}$ M.SC.

\begin{abstract}
1Doutorando Universidade Estadual Paulista "Júlio de Mesquita Filho", campus Jaboticabal - SP, ${ }^{2}$ Profesor Faculdade de Ciências Agropecuarias Universidade de Sucre, Colômbia, ${ }^{3}$ Departamento de Zootecnia Instituto Federal de Educação, Ciência e Tecnologia do Sudeste de Minas Gerais, Campus de Rio Pomba, IF SEMG, ${ }^{4}$ Professor Faculdades Associadas de Uberaba - FAZU - MG, ${ }^{5}$ Doutorando Universidade Estadual Paulista "Júlio de Mesquita Filho", campus Jaboticabal - SP, ${ }^{6}$ Professor Universidade Federal Rural da Amazônia - UFRA PA.

Correspodência: ericvancleef@gmail.com
\end{abstract}

\begin{abstract}
Resumo
$\mathrm{Na}$ bovinocultura chamada "elite", os problemas metabólicos são freqüentes devido à necessidade de se obter um animal que apresente um elevado desempenho. Um dos principais problemas encontrados nesse tipo de atividade é o excessivo fornecimento de alimentos concentrados. Dentre os principais distúrbios metabólicos, pode-se destacar a acidose ruminal, timpanismo, cetose e lipidose hepática. Os prejuízos que tais distúrbios promovem, raramente são visíveis, já que na maioria das vezes, essas doenças não apresentam sinais clínicos. Existem maneiras de manipular o rúmen para minimizar os distúrbios metabólicos, que podem ser ao nível animal, da dieta ou dos microorganismos ruminais, como por exemplo, a utilização de certos alimentos na alimentação dos animais. Mais pesquisas são necessárias para que a influência do manejo nutricional, visando evitar distúrbios metabólicos, seja completamente entendida.
\end{abstract}

Palavras chave: concentrados, nutrição, ruminantes 


\title{
Resumen
}

En las Ilamadas ganaderías "elite" los problemas metabólicos son frecuentes debido a la necesidad de obtener un elevado desempeño animal. Uno de los principales problemas observados en esos sistemas es la elevada oferta de alimentos concentrados. Dentro de los principales desórdenes metabólicos se destacan la acidosis ruminal, timpanismo, cetosis e hígado graso. Los perjuicios ocasionados por estos problemas no son visibles, ya que muchas veces no aparecen síntomas clínicos. Existen formas de manipular el rumen para evitar estos trastornos, a través de la dieta, del animal o de los microorganismos ruminales, como puede ser el uso de ciertos alimentos. Son necesarias más investigaciones sobre la influencia del manejo alimenticio para evitar la incidencia de estos disturbios y poder entenderlos mejor.

Palabras clave: concentrados, nutrición, problemas metabólicos

\begin{abstract}
In the "top" cattle farming, the metabolic problems are frequent due to the necessity of getting an animal that presents a high performance. One of the main problems found in this type of activity is the extreme concentration of food supply. Among the main metabolic disorders are ruminal acidosis, bloat, ketosis and hepatic lipidosis. The metabolic disorders' damages are rarely visible because, most of times, these illnesses don't show clinical signals. There are ways to manipulate the rumen to minimize the metabolic disorders that can be at the animal level, the diet or rumen microorganisms, such as the use of residues and by-products from the agro-industry in the animal feeding. More researches are necessary to completely understand the influence of the nutrition handling on the metabolic disorders.
\end{abstract}

Key - words: concentrate, nutrition, ruminants.

\section{Introdução}

A nutrição é a base para a produção animal. No Brasil a nutrição de ruminantes, em sua maior parte, é baseada em pastagens tropicais. O manejo nutricional é, atualmente, uma das áreas mais estudadas pelos pesquisadores que atuam no cenário da pecuária nacional.

A busca pela melhoria das condições de criação para que os animais possam expressar seu potencial genético é um dos maiores objetivos de todos os profissionais envolvidos na cadeia de produção de ruminantes. 
Dentre os aspectos mais importantes no cenário atual destaca-se o problema da alimentação dos rebanhos, expressivo componente do custo de produção de qualquer sistema de produção animal. Sua importância é fator determinante do êxito ou fracasso da atividade em questão, e pode levar a decisões diversas, como a busca por novas oportunidades em regiões distantes.

A nutrição animal é uma atividade que exige conhecimento científico para o desenvolvimento de técnicas e tecnologias (formulação de dietas e suplementos) para nutrir os animais de interesse.

A utilização de dietas ricas em fibras ou concentradas induz a alterações na fisiologia ruminal, uma vez que, dependendo do alimento, altera-se a população de microorganismos, taxa de passagem do alimento, motilidade e velocidade de absorção dos nutrientes. Estes fatores podem causar uma série de distúrbios metabólicos que podem acarretar em perda de eficiência e produção dos animais, e consequentemente, prejuízos econômicos para os produtores.

Na bovinocultura chamada "elite", estes problemas metabólicos são freqüentes, devido à necessidade de se obter um animal que apresente um elevado ganho em peso diário. Um dos principais problemas encontrados nesse tipo de atividade é o excessivo fornecimento de alimentos concentrados. Outro problema é a falta de profissionais qualificados para formular dietas que a prejudiquem e nem comprometam os animais.

Neste sistema de produção de gado "elite", onde objetiva-se a maximização individual do animal ocorre uma maior predisposição a distúrbios metabólicos, e cabe aos nutricionistas encontrarem soluções para minimizar as perdas econômicas que são conseqüências deste tipo de problema.

\section{Conceitos relacionados às doenças da produção}

As doenças relacionadas à produção são transtornos metabólicos que se apresentam em um grupo de animais de produção, induzidos por medidas de seleção ou manejo, e que têm como causa um desequilíbrio entre a entrada de um ou mais nutrientes ao organismo, sua biotransformação e a saída do organismo (WITTWER, 2000).

O conceito de transtorno metabólico nutricional deve ser entendido em forma diferente se referido a um indivíduo ou a um grupo de indivíduos em um sistema produtivo. No primeiro caso, o transtorno é considerado como doença metabólica, que se trata da alteração da capacidade de homeostase em um indivíduo produto 
da mudança no grau de transformação de um processo metabólico relacionado com um nutriente (OYARZUN, 1997). Entretanto, quando se refere ao rebanho, este transtorno passa a ser chamado de doença de produção e é caracterizada pelo desequilíbrio entre o volume de entrada (aporte e consumo da dieta), circulação (transporte e biotransformação) e saídas (resíduos metabólicos e produção) de um nutriente em um grupo de animais de um sistema produtivo (SEGLAR, 1997)

WITTWER (2000) descreveu que a capacidade de um animal para se ajustar a um balanço negativo depende do volume de suas reservas corporais disponíveis. Pelo contrário, a adaptação a um balanço positivo depende de sua capacidade metabólica para armazenar reservas. Os balanços nutricionais negativos são as causas da maioria das doenças de produção. Embora seja normal algum grau de deficiência em alguns períodos, especialmente no início da lactação, a linha entre normalidade e doença é facilmente atravessada (WOLFF et al., 1978).

WITTWER (1996) elaborou um quadro com as principais doenças metabólicas que ocorrem nos rebanhos de alta produção (Quadro 1).

Quadro 1. Problemas metabólicos de animais de alta produção.

\begin{tabular}{|c|c|c|}
\hline Entrad as & Circulação & Saíd as \\
\hline $\begin{array}{l}\text { Apetite aumentado } \\
\text { Sobrecarga numinal } \\
\text { Fermentação instável } \\
\text { Acidose } \\
\text { Úlsera solar }\end{array}$ & 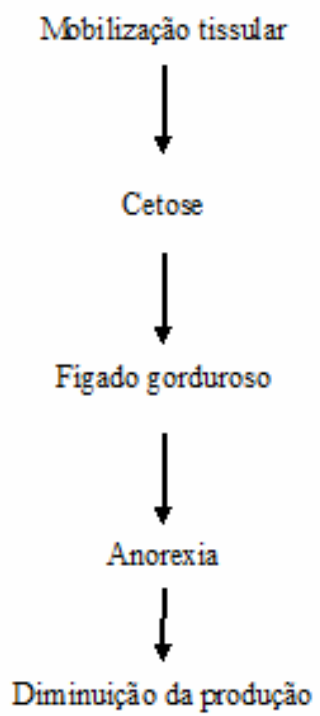 & $\begin{array}{l}\text { Elevada produção } \\
\text { Excessiva perda de peso } \\
\text { Fertilidade reduzida }\end{array}$ \\
\hline
\end{tabular}

Fonte: WITTWER, 1996. Adaptado. 
Segundo VOGEL e PARROT (1994), em animais confinados, a mortalidade associada a doenças digestivas perde apenas para as associadas a doenças respiratórias. Estes autores realizaram uma pesquisa que englobou 59 confinamentos e registraram que as mortes por causas digestivas variaram de 0,05 a $0,08 \%$ do total, representando $26 \%$ das mortes.

Segundo NAGARAJA (2007a) os problemas digestivos retículo-ruminais podem ser divididos em duas categorias. A primeira é a de problemas relacionados à motilidade, que se caracteriza pela deficiência nas contrações (freqüência, amplitude) ou ausência de contrações (paralisia ruminal) resultantes de causas como: mecânica, metabólica, infecciosa ou desconhecida. Alguns exemplos são: indigestão vagal (causada por trauma no nervo vago), torção gástrica (causada por hipocalcemia), reticuloperitonite ou reticulopericardite. Já a segunda categoria é a das desordens fermentativas, caracterizadas por alterações no rumen e em suas atividades, que resulta em condições desfavoráveis para o hospedeiro e podem causar desde perda de apetite até morte.

As doenças fermentativas, nas quais, os microorganismos ruminais têm papel principal, podem ser agrupadas em quatro grupos. O primeiro é caracterizado pelo acúmulo excessivo de produtos da fermentação, como: ácidos orgânicos, gases e amônia. No segundo grupo cita-se a produção de toxinas. As transformações microbianas de certos componentes não-tóxicos das rações em componentes tóxicos e sua absorção a partir do rúmen levam ao aparecimento de toxicoses. Alguns exemplos de compostos tóxicos são os nitritos, alcalóides produzidos durante a amonização de forragens, o 3-metilindol, compostos pneumotóxicos, histamina e metabólitos e toxinas de plantas. O terceiro grupo é composto pela destruição de produtos benéficos. $O$ quarto grupo descrito, cita os patógenos oportunistas. Quando as condições se tornam favoráveis, certos microorganismos, como os Aspergillus spp. Ou o Fusobacterium necrophorum, invadem o epitélio ruminal e causam rumenites. Além disso, à partir da parede ruminal, os Fusobacterium necrophorum podem entrar na circulação portal, alcançar o fígado e causar abcessos (NARAGAJA, 2007ª).

Algumas doenças fermentativas acometem os ruminantes através do consumo de forragens ou cereais, causando-lhes prejuízos na digestão através do gasto de energia, conforme pode ser observado na Tabela 1. 
Tabela 1. Desordens fermentativas em ruminantes alimentados com forragens ou cereais.

\begin{tabular}{|l|c|c|}
\hline \multicolumn{1}{|c|}{ Desordem } & Forragem & Cereais \\
\hline Edema pulmonar bovino agudo e enfisema & Sim & Não \\
\hline Timpanismo & Sim & Não \\
\hline Toxidade da uréia ou da amônia & Sim & Raro \\
\hline Toxidade dos nitratos & Sim & Raro \\
\hline Toxicose do feno amoniatado & Sim & Não \\
\hline Toxicose vegetal & Sim & Raro \\
\hline Acidose & Não & Sim \\
\hline Rumenite & Não & Sim \\
\hline Laminite & Não & Sim \\
\hline Abcesso hepático & Não & Sim \\
\hline Poliencefalomalácia & Não & Sim \\
\hline Timpanismo de cereais & Não & Sim \\
\hline Síndrome da morte súbita & Não & Sim \\
\hline
\end{tabular}

Fonte: NAGARAJA (2007a). Adaptada.

\section{Acidose ruminal}

A acidose ruminal é uma doença metabólica de evolução aguda ou crônica, causada pela ingestão abrupta, sem prévia adaptação de alimentos ricos em carboidratos, os quais, fermentados no rúmen, produzem grandes quantidades de ácido lático, provocando inicialmente acidose ruminal e atonia neste órgão, seguida de acidose sistêmica, desidratação, prostração, coma e, freqüentemente, morte (MARUTA e ORTOLANI, 2002).

Segundo OWENS et al. (1998), as alterações nas características físico-químicas do suco ruminal estão relacionadas com a diminuição do $\mathrm{pH}$ causada pela excessiva elevação na concentração do ácido lático (rápida proliferação de bactérias Gram-positivas Streptococcus bovis e Lactobacillus $s p$ ) no rúmen, que altera a osmolaridade do meio, aumentando-a, tornando o meio hipertônico em relação ao plasma.

A acidose é uma enfermidade de grande impacto econômico, pois acomete normalmente os bovinos mantidos em sistemas de confinamento e alimentados 
com dietas hiperglucídicas com a finalidade de atingirem seu peso e o seu potencial máximo (MILLEO et al., 2006). Na Fig. 2 são apresentados fatores que levam a sinais clínicos da acidose.

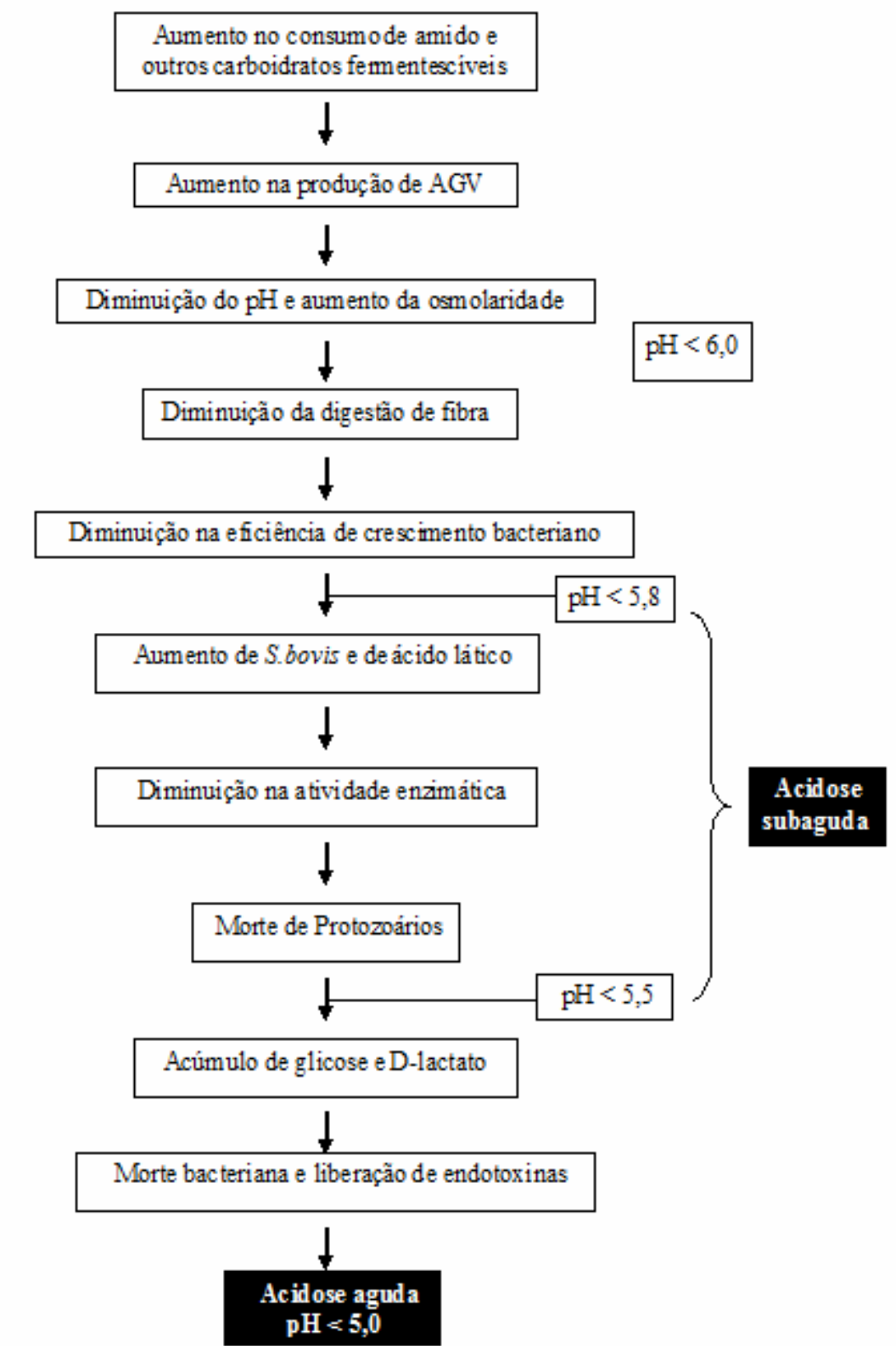

Figura 2. Diagrama da acidose ruminal causada pelo consumo excessivo de carboidratos (Adaptado de SANTOS (2006).

Segundo SANTOS (2006), na forma aguda do distúrbio, há um aumento exacerbado na osmolaridade ruminal, assim como acúmulo de glicose e lactato 
nas suas duas formas estequiométricas, o D-lactato e o L-lactato no líquido ruminal. Na forma subaguda, há um pequeno acúmulo de ácido lático no rúmen, e grande parte da alteração no ambiente ruminal é devida ao acúmulo de grandes concentrações de ácidos graxos voláteis.

\section{Timpanismo}

O timpanismo é um transtorno digestivo que acomete os ruminantes. É causado por uma excessiva retenção de gases da fermentação microbiana, que provoca uma distensão anormal do retículo-rúmen, causando perdas econômicas significativas já que ocorre perda de produção e elevada mortalidade de animais gravemente afetados (BAVERA e PEÑAFORT, 2007).

A etiologia da doença está associada a fatores que impeçam o animal de eliminar gases produzidos durante a fermentação ruminal. O timpanismo pode ser classificado em primário ou secundário. O primário é caracterizado pelo aumento na tensão superficial do líquido ruminal ou de sua viscosidade, que faz com que as bolhas de gases presentes na espuma, persistam por longos períodos dispersos na ingesta e, apesar dos movimentos contínuos do conteúdo ruminal, estas não se desfazem, impossibilitando sua eliminação (BAVERA e PEÑAFORT, 2007).

Um dos fatores que podem influenciar este aumento de viscosidade, principalmente a campo, é o que está relacionado a certas proteínas presentes nas plantas, particularmente nas leguminosas (TEIXEIRA, 1997).

Alterações na quantidade e qualidade da saliva produzida podem também influenciar na formação de bolhas e no desenvolvimento do timpanismo. Isto pode ser devido à ação da saliva sobre o pH do conteúdo ruminal, que tem importante papel na estabilidade da espuma, ou devido ao conteúdo de mucoproteínas da mesma. Animais que produzem menos saliva são mais susceptíveis (CHENG et al., 1998).

Acredita-se que a origem da espuma em animais confinados esteja relacionada ao aumento da população de certas bactérias produtoras de muco ou à retenção de gases produzidos pelos alimentos finamente moídos. Já HIRONAKA e FREEZE (1992) relataram que as bactérias e protozoários ruminais respondem a uma alimentação com partículas finas, com a produção de uma secreção viscosa que prende o gás produzido durante o metabolismo normal destes microorganismos, causando o timpanismo. 
O timpanismo secundário ocorre quando há dificuldade física à eructação. Isto pode ser determinado por uma obstrução do esôfago por corpo estranho, como complicação de doenças que podem levar a enfartamento ganglionar (leucose, tuberculose, actinobacilose, pneumonia etc.) ou por lesão nas vias nervosas responsáveis pelos processos de eructação (indigestão vagal, reticulites etc.). $O$ tétano, devido ao espasmo de musculatura, também pode causar a doença (GEORGE, 1993).

O timpanismo afeta bovinos de ambos os sexos e de todas as raças e idades, havendo variações em relação aos animais (idade e susceptibilidade) e em relação ao meio ambiente, como clima, solo e tipo de forragem (MAJAK et al., 2001). A incidência tem se mostrado alta em bovinos mantidos em sistemas de confinamento e recebendo dietas ricas em concentrados, especialmente cevada ou soja, ou em pastagens de leguminosas em alto grau de crescimento (CHENG et al., 1998).

A ingestão de grandes quantidades de produtos altamente fermentáveis, em um curto espaço de tempo, leva à formação de grandes volumes de ácidos graxos voláteis resultantes do processo de fermentação pela microflora ruminal. $\mathrm{O} p \mathrm{pH}$ ruminal baixa até seis, fazendo com que a produção de dióxido de carbono e de bicarbonato salivar seja acelerado. Ocorre formação de uma espuma densa, levando à distensão do rúmen até a sua capacidade máxima em função da contínua produção de gases, interferindo mecanicamente com os sistemas respiratório e circulatório do animal (CHENG et al., 1998).

A morte provavelmente seja causada pela combinação dos efeitos mecânicos, resultantes da distensão exagerada do rúmen, e dos efeitos bioquímicos, resultantes da absorção de gases tóxicos pela mucosa ruminal, como dióxido de carbono, ácido sulfídrico e amônia. As perdas por timpanismo podem chegar a 2,6\% (BAVERA e PEÑAFORT, 2007).

A excessiva pressão intra-ruminal leva a uma distensão do flanco esquerdo e causa uma situação de desconforto para o animal, que faz com que o mesmo pare de se alimentar e apresente sintomas de dor abdominal, escoiceando o ventre e emitindo grunhidos. A freqüência respiratória aumenta e é acompanhada de respiração oral, protrusão (exteriorização) da língua, salivação, extensão do pescoço e distensão dos membros. Os movimentos ruminais estão aumentados nas fases iniciais, diminuindo então de intensidade, chegando até a atonia em função da distensão acentuada do rúmen. O quadro evolui para a queda do 
animal, com a cabeça distendida, boca aberta, língua protrusa e olhos dilatados. A morte ocorre após algumas horas do início dos sintomas (HOWARTH et al., 1986).

O diagnóstico de timpanismo normalmente não é tão simples, pois muitas doenças apresentam sintomas parecidos, principalmente na forma subaguda. Em alguns animais superalimentados, a distensão de fossa paralombar pode não ser tão evidente, fazendo com que a verdadeira causa da morte do animal seja negligenciada. Já a forma aguda da doença pode ser diagnosticada sem problemas através de um exame externo (SPRINKLE, 1999).

O tipo de tratamento a ser feito varia de acordo com o tipo de timpanismo e o grau de severidade do caso. Muitas vezes, os sintomas só são observados em condições avançadas, quando se torna necessário o uso de medidas de emergência para que se consiga salvar o animal. $O$ tratamento do timpanismo de origem alimentar é feito com substâncias que facilitam a expulsão dos gases retidos (substâncias antiespumantes), devendo-se retirar o alimento causador do problema da dieta alimentar até sua recuperação. Os antiespumantes existentes no comércio são, na sua maioria, à base de silicone, podendo ser usados puros ou diluídos em água morna (MAJAK et al., 1995). A sonda pode ser utilizada para o tratamento do timpanismo gasoso (SPRINKLE, 1999).

A maneira mais indicada de se prevenir o problema é evitar a adoção de dietas com excesso de grãos e deficiente em fibras, assim como a excessiva moagem dos grãos. O cuidado no uso de feno de leguminosas, embora de pouco uso em confinamentos em nosso país, também vale a pena ser comentado, para o caso de animais estabulados.

A utilização de antibióticos com o objetivo de controlar a atividade bacteriana e a produção de gás no rúmen, tem se mostrado pouco praticável, em função da necessidade de um longo período de proteção. $A$ inclusão de óleos na ração pode apresentar algum efeito profilático, embora apresente algumas desvantagens, tais como dificuldade de administração e curto período de proteção. $O$ uso de ionóforos (monensina, lasalocida) na ração de bovinos confinados tem auxiliado na diminuição da incidência de timpanismo (MACHADO e MADEIRA, 1990).

\section{Cetose}

Os sistemas de produção que objetivam a maximização da produção individual do animal têm-se deparado, na última década, com o desafio de alimentar um animal de extrema capacidade produtiva, sobretudo nos primeiros meses de lactação. $O$ aumento da demanda energética no final da gestação, uma maior predisposição a 
mobilização de gordura corpórea e a redução da capacidade ingestiva nas últimas semanas antes do parto são fatores que quando reunidos colocam o animal em uma situação de extremo desafio, predispondo-o a diversos distúrbios metabólicos e suas implicações (JUCHEM et al., 2000).

No período entre o final da gestação e o início da lactação em vacas leiteiras especializadas, existe maior risco de doenças metabólicas, quando comparadas com outras fases do ciclo de lactação (CONTI et al., 2002).

Segundo DUFFIELD et al. (1999), as principais predisposições a estes distúrbios são: a extrema demanda de energia com maior mobilização de gordura corpórea e a redução na capacidade de ingestão de matéria seca, afetando a produção leiteira e a reprodução.

A cetose e a lipidose hepática são doenças inter-relacionadas, associadas ao balanço energético negativo e à carência de carboidratos precursores de glicose, típicas do periparto de vacas de alta produção leiteira. Neste período ocorre também a época de reprodução, fato importante a considerar, uma vez que o aumento das demandas metabólicas diminui a fertilidade das vacas (WITTER, 2000).

A cetose é uma doença relativamente comum em vacas de alta produção leiteira, sendo as multíparas mais afetadas que as primíparas. Geralmente, a enfermidade ocorre entre os dias 8 e 60 do pós-parto, período que o animal enfrenta um balanço energético negativo (GONZÁLEZ e CAMPOS, 2003).

Vacas em início da lactação têm o apetite influenciado pelas concentrações de hormônios estrogênicos e outros fatores característicos deste estado. Neste período, a prioridade dos nutrientes disponíveis no metabolismo do animal é para manter a lactação (AROEIRA, 1998).

A cetose começa a ser moléstia apenas quando a absorção e a produção de corpos cetônicos chegam a exceder seu consumo pelo ruminante como fonte de energia, o que resultará em elevados níveis sangüíneos de corpos cetônicos e de ácidos graxos livres ou não esterificados e hipoglicemia (FLEMING, 1993). Vacas de alta produção leiteira geralmente apresentam algum nível de cetose durante a curva ascendente de lactação (TEIXEIRA, 1997).

Os corpos cetônicos são substâncias formadas a partir do metabolismo das gorduras e do butirato e são representados pelo $\beta$-hidroxibutirato, acetoacetato e acetona. $O$ acetoacetato é quimicamente instável e pode ser transformado em 
acetona e dióxido de carbono. Normalmente, os corpos cetônicos são formados em pequena quantidade no organismo. Em caso de grande mobilização de gorduras, como ocorre na cetose bovina e na toxemia da prenhez dos pequenos ruminantes, ele se acumula no organismo causando graves transtornos como acidose metabólica e distúrbios cerebrais (AROEIRA, 1998).

Segundo AROEIRA (1998), existem alguns fatores predisponentes para a ocorrência da cetose, entre eles pode-se citar: idade do animal, o número de lactações, estado corpóreo, ingestão de matéria seca no período pré-parto e produção láctea.

Vacas de qualquer idade podem ser acometidas, mas a doença progride de uma baixa prevalência no primeiro parto até um pico no quarto parto. Entretanto, a cetose e a esteatose hepática não é comum em novilhas de primeira lactação (DUFFIELD et al., 1999).

A cetose clínica pode ser classificadas em quatro tipos: primária, secundária, alimentar e espontânea. Na primária, a vaca não recebe a quantidade de alimentos adequados. Na secundária, a ingestão de alimentos é diminuída em conseqüência de outra doença. Na alimentar, a ingestão é rica em precursores cetogênicos e na espontânea a vaca apresenta elevadas concentrações de corpos cetônicos no sangue, mesmo ingerindo uma dieta aparentemente adequada (AROEIRA, 1998).

A cetose subclínica pode ser definida como um estágio pré-clínico da cetose, caracterizando-se por uma elevação dos corpos cetônicos no sangue sem as manifestações clínicas da doença. Os sinais clínicos mais característicos da doença, além do odor de acetona no hálito e na urina, são: perda de apetite, especialmente por concentrados, diminuição da produção leiteira e rápida perda de condição corporal. Alguns animais tornam-se excitados, embora a maioria permaneça apático. A temperatura corporal permanece dentro dos limites fisiológicos (TEIXEIRA, 1997).

FLEMING (1993) descreveu como sinais clínicos fezes secas e firmes, depressão moderada e, por vezes, relutância em se movimentar. A motilidade ruminal poderá estar reduzida se o animal estiver anoréxico há vários dias. Pode-se observar depravação do apetite. $O$ odor de corpos cetônicos poderá ser detectado na respiração, no leite e na urina. Sinais clínicos nervosos como cambaleio e cegueira eventualmente poderão ocorrer em alguns períodos da doença. 
O acúmulo de corpos cetônicos promove uma acidose metabólica nos animais acometidos de cetose. Segundo ORTOLANI (2003), a geração de outros ácidos orgânicos, que não $O$ ácido láctico, também ocorre com alguma freqüência em ruminantes, sendo mais comuns a cetoacidose presente em ovelhas e cabras com toxemia da prenhez e na acetonemia ou cetose da vaca leiteira.

A disponibilidade de glicose parece ser o fator limitante para a produção de leite e o suprimento dela depende da gliconeogênese, que por sua vez, é estimulada pelo glucagon e inibido pela insulina. A cetogênese depende dos hormônios reguladores da glicose no sangue. No entanto, no início da lactação, as concentrações de glicose, de insulina e a taxa de insulina glucagon são baixas e aumentam com a progressão da lactação. Nesta fase o hormônio de crescimento e as taxas de hormônio de crescimento/insulina são elevadas e decrescem com a evolução da lactação (AROEIRA, 1998).

GONZÁLEZ e CAMPOS (2003), apontaram que o leite tem sido muito utilizado para o diagnóstico de cetose. No entanto, os autores ressalvam que a cetose é uma doença que se desenvolve sem um diagnóstico seguro, já que a maioria dos casos são apresentados na forma subclínica, podendo chegar a $34 \%$ dos casos, enquanto que os clínicos apresentam-se em média de 7\%. Estes autores apresentaram um amplo estudo para testes de deteç̧ão de cetose subclínica, utilizando tiras ou tabletes tanto no leite como no sangue para detectar acetoacetato, $\beta$-hidroxibutirato e acetona. A dosagem do $\beta$-hidroxibutirato no leite mostrou sensibilidade e especificidade na detecção de cetose em vacas leiteiras.

A urina apresenta-se de forma eficiente no diagnóstico da cetose. O ideal é após a colheita da urina, que seja realizado o mais rápido possível a análise de corpos cetônicos, pois estas substâncias são muito voláteis (acetona) ou de certa instabilidade química (acetoacetato). A análise destas substâncias, cerca de 30 minutos após a colheita reduz suas concentrações em até $40 \%$ (ORTOLANI, 2003).

Parte dos corpos cetônicos pode ser utilizada como forma de energia pelos diversos tecidos, inclusive o renal. Cerca de $10 \%$ dos corpos cetônicos são excretados pela urina, leite e ar exalado. Pequenas quantidades de corpos cetônicos no sangue não chegam a alcançar a urina, pois mesmo sendo filtrados pelos glomérulos, em seguida são reabsorvidos pelos túbulos renais. Em altas concentrações, os corpos cetônicos ultrapassam os limiares renais, sendo excretados em abundância (principalmente acetona e acetoacetato). Para quatro moles de corpos cetônicos na urina encontra-se 1 no sangue e 0,5 no leite. Em 
casos de suspeita de cetose, deve-se fazer a primeira triagem pela urina (ORTOLANI, 2003).

Geralmente, casos de cetose clínica, apresentam concentrações glicêmicas de 20 a $40 \mathrm{mg} / \mathrm{dL}$, os corpos cetônicos totais acima de $30 \mathrm{mg} / \mathrm{dL}$, corpos cetônicos urinários acima de $80 \mathrm{mg} / \mathrm{dL}$ e corpos cetônicos totais acima de $10 \mathrm{mg} / \mathrm{dL}$ (FLEMING, 1993).

A determinação do $\beta$-hidroxibutirato é feita através de técnica espectrofotométrica ultravioleta no sangue. Também tem sido relatado que testes de determinações semiquantativas de $\beta$-hidroxibutirato em amostras de leite, mediante química seca apresentam-se ser métodos sensíveis, simples, prático e rápido para se obter um controle preventivo da cetose subclínica em vacas leiteiras, requerendo ainda maiores informações sobre esta técnica para utilização em nossas condições (WITTWER, 2000).

A somatrotopina bovina (BST), produzida através da técnica do DNA recombinante, representa um dos primeiros produtos da biotecnologia utilizados na produção animal. O aumento da produção de leite promovido pelo BST é uma conseqüência de dois mecanismos de ação: partição de nutrientes (envolvendo adaptações metabólicas em vários tecidos) e efeito mitogênico (GAMA et al., 2001). Sua administração para vacas leiteiras têm resultado em aumentos sem precedentes na produção de leite e na eficiência produtiva dos animais (BAUMAN, 1992).

Segundo AROEIRA (1998), vacas que receberam na lactação anterior BST apresentaram maiores ingestões de alimentos, menores concentrações de ácidos graxos livres e corpos cetônicos, além de uma glicemia mais elevada, concluindo na sua revisão bibliográfica, que o BST pode exercer um benefício na redução do risco de doenças metabólicas associadas à mobilização de lipídios no pós-parto.

A utilização de vitaminas do complexo B na alimentação de vacas leiteiras tem ajudado a evitar maiores complicações e manter o desempenho produtivo do rebanho. Dentre elas, a niacina (B3), nome genérico do ácido nicotínico e da nicotinamida, tem desenvolvido importante papel na alimentação de vacas de alta produção, interferindo no processo de mobilização de reservas energéticas e de gordura, contribuindo para a diminuição do surgimento de cetoses (BORGES, $\left.2003^{a}\right)$. 
A niacina faz parte do sistema de coenzimas que atua no metabolismo de carboidratos, lipídeos, proteína, formação de ATP e regulação enzimática. Desta forma, a utilização de niacina na dieta pode previnir a cetose, diminuindo a formação de ácidos graxos não esterificados, mantendo o nível de glicose no sangue e o consumo de matéria seca. A recomendação atual é fornecer de 6 a 12 gramas de niacina por dia, iniciando 21 dias antes da data provável do parto até - $30^{\circ}$ dia de lactação, principalmente para vacas de alta produção ( $>32 \mathrm{~kg}$ leite/dia) e vacas de primeira cria produzindo acima de $25 \mathrm{Kg} / \mathrm{dia}$, bem como as vacas obesas (HUTJENS, 1992).

O resultado do uso de niacina como suplemento apresenta-se de forma bastante rápida, sendo de grande importância para o criador, onde os animais que podem responder economicamente incluem-se os rebanhos de alta produção, vacas com balanço energético negativo, vacas com tendência a cetose, vacas secas com grande deposição de gordura e vacas com baixo consumo de matéria seca no início da lactação (BORGES, 2003ª).

Nos últimos anos, uma série de trabalhos envolvendo a administração de compostos gluconeogênicos, modificadores de fermentação ruminal, manipulação de dietas pré e pós-parto tem buscado esclarecer este assunto mais detalhadamente. Dois produtos têm sido freqüentemente citados como alternativas potenciais para este problema, um pela capacidade gluneogênica intrínseca (propileno-glicol) e o outro pela alteração fermentativa que produz no rúmen (monensina), favorecendo a maior participação de ácido propiônico no "pool" ruminal (JUCHEM et al., 2000).

A monensina sódica promove a redução de distúrbio ruminais como a acidose lática e a cetose (PEREIRA et al., 2001). FERREIRA e DEL'PORTO (1999) descreveram os ionóforos com compostos lipossolúveis que podem agir formando canais ou poros que permitem o transporte de íons. $O$ transporte de íons através da membrana compromete a produção de ATP pelas mitocôndrias, exaurindo, desta forma, a fonte de energia dos parasitos (bactérias gram-positivas). A ação dos ionóforos no rúmen dos animais depende basicamente da afinidade que cada droga possui em relação aos íons (BORGES, 2003b).

Segundo TEIXEIRA (1997) o tratamento da cetose pode ser feito através de: glicose intravenosa (embora seja um processo difícil em condições de campo); hormônios (o efeito benéfico de glicocorticóides parece ser devido ao aumento de glicose no sangue através da estimulação da gliconeogenese de aminoácidos). $O$ propilenoglicol é convertido à glicose no fígado. A vantagem dos produtos orais é 
que uma fonte de glicose exógena é fornecida sem um nível moderado por um período prolongado (TEIXEIRA, 1997).

AROEIRA (1998) citou que o aumento dos corpos cetônicos no leite está associado a uma diminuição da produção de 1 a $1,4 \mathrm{~kg}$ de leite/dia e as perdas totais de $233 \mathrm{~kg}$ de leite nos primeiros cem dias de lactação.

\section{Lipidose hepática}

Esta doença é provocada pelo desequilíbrio entre a captação hepática dos ácidos graxos e sua utilização (AROEIRA, 1998). A presença excessiva de lipídios dentro do fígado é denominada de lipidose hepática ou degeneração gordurosa e ocorre quando o índice de acumulação de triglicerídios excede seus índices de degradação metabólica ou liberação como lipoproteínas. As principais doenças que podem causar lipidose hepática são: síndrome da vaca gorda, toxemia da prenhez em vacas de corte, toxemia da prenhez em ovelhas e cabras e cetose dos bovinos (MACLACHLAN e CULLEN, 1998).

O fígado deve processar não apenas os quilomicrons e ácidos graxos voláteis absorvidos, mas também grande parte dos ácidos graxos livres e do glicerol decorrentes da mobilização da gordura do tecido adiposo. O fígado dos grandes herbívoros tem funções únicas, visto que grande parte da energia nutricional é absorvida em forma de ácidos graxos voláteis, e não como glicose (PEARSON e MAAS, 1993).

Nos períodos de balanço energético negativo, a gordura é mobilizada para que haja ácidos graxos livres (AGL), ácidos graxos não esterificados (AGNE) e glicerol como substratos de energia. No fígado, o glicerol pode ser usado na produção de glicose, ou ser recombinado com AGL e AGNE para a síntese de triglicerídios (MACLACHLAN e CULLEN, 1998).

O fígado utiliza a $\beta$-oxidação dos AGL e dos ácidos de cadeia longa ( $A G C L)$ para obtenção de energia. Dois ácidos de dois carbono convertidos até acetil-CoA combinam com o oxaloacetato, para ingresso no ciclo de Krebs. Parte do ácido oxaloacético pode ser usado para a gluconeogênese, limitando a quantidade de acetil-CoA derivada da $\beta$-oxidação, que pode ingressar no ciclo de Krebs (PEARSON e MAAS, 1993).

O excesso de acetil-CoA é incompletamente oxidado até a formação de corpos cetônicos. Os triglicerídios eventualmente deixam o fígado, como lipoproteínas de densidade muito baixa (VLDL), que são complexos plasma solúveis de 
fosfolipídios, colesterol, triglicerídios e apoproteínas. A lipidose hepática ocorre quando a velocidade de formação de triglicerídios hepáticos excede a oxidação dos AGCL e a formação e liberação das VLDL para a circulação periférica (MACLACHLAN e CULLEN, 1998).

Todas as vacas leiteiras com elevada produção apresentam quantidades de gordura aumentadas (15 a 32\%) no fígado antes do parto e durante as primeiras semanas após o parto.

A lipidose hepática parece ser reversível se for removida a causa e se o equilíbrio energético for retomado (PEARSON e MAAS, 1993). Segundo os mesmos autores, o mais importante para o tratamento da lipidose hepática é a eliminação do equilíbrio energético negativo e as moléstias que causam este desequilíbrio.

\section{Manipulação do rúmen para minimizar problemas}

Segundo NAGARAJA (2007b), a manipulação da fermentação ruminal tem sido tópico de muita investigação das últimas décadas e tem por objetivos: maximizar a eficiência da utilização dos alimentos, minimizar os problemas e aumentar a produtividade do ruminante, ou seja, aumentar a produção de leite e carne.

A fermentação ruminal pode ser manipulada através de intervenções em três níveis: dietético, animal e microbiano, sendo que as duas primeiras abordagens têm impacto direto na fermentação ruminal através da alteração na alimentação e da fisiologia do ruminante; e a terceira é mais direta, alterando o padrão de fermentação através da ação de certos componentes da população microbiana (NAGARAJA, 2007b).

Segundo BROWN et al. (2006), quando se muda a dieta baseada em pastagens para uma dieta rica em cereais o rúmen fica sujeito a alterações profundas na população microbiana e nos produtos de sua fermentação. Os autores citaram que não é surpresa que as desordens fermentativas ruminais ocorram normalmente durante este processo de transição. Eles acreditam que programas prudentes de transição podem minimizar os problemas e que um programa efetivo depende de vários fatores como: tipo de cereal, tipo de processamento de grãos, freqüência alimentar, nível alimentar e tipo e nível de pastagem.

Uma alternativa para minimizar os problemas fermentativos ruminais é regular a ingestão alimentar sem comprometer o ganho de peso e a eficiência da alimentação. Alimentação restritiva reduz flutuações no volume ingerido, pelo menos em confinamentos, embora não regule ingestão individual. Esta não é uma 
alternativa para minimizar desordens fermentativas em animais "elite", já que estes não passam por restrição alimentar devido a fatores que englobam: mentalidade dos criadores, tabelas de pesos, entre outros (NAGARAJA, 2007b).

Os nutricionistas podem e devem formular dietas com diversos tipos de cereais e com diferentes tipos de processamento que podem influenciar na taxa e na extensão da fermentação do amido no rumem ou após o mesmo, de modo a prevenir ou controlar problemas digestivos ruminais (STOCK et al., 1987).

Tem-se demonstrado também, que misturas de dois tipos de grãos ou métodos de processamento, onde um é geralmente de fermentação rápida (trigo, cevada) e outro de fermentação mais demorada (milho, sorgo) otimizam a fermentação ruminal do amido e reduzem a incidência de acidose (STOCK et al., 1987).

Segundo NAGARAJA (2007b), a forragem, em uma dieta rica em cereais, tem duas funções: estimular mastigação e possivelmente a ruminação, promovendo um aumento na produção de saliva, o que ajuda a aumentar a capacidade do rúmen e estimular mecanicamente as papilas do rúmen. Segundo ZINN et al. (1994), ao aumentar o nível de forragem de 15 para $20 \%$, reduziria a incidência de acidose e também reduziria o crescimento e conversão alimentar.

Existem métodos para que haja uma intervenção no nível animal. Entre eles se destacam: uso de substâncias que estimulam o aumento na ingestão de alimentos, como os subprodutos e resíduos (BAILE e McLAUGHLIN, 1978); uso de substâncias que proporcionam aumento na produção salivar, como a pilocarpina (NARAGAJA, 2007b) e o uso de substâncias que influenciam nas atividades funcionais do estômago, tais como motilidade retículo-ruminal e funções metabólica e absorvente do epitélio ruminal, conseguidas através de estimulação química (RUCKEBUSH et al., 1985).

Várias são as substâncias que podem ser utilizadas para intervir na população e atividade microbiana, entre eles: compostos tampão, como $\mathrm{NaHCO}_{3}, \mathrm{CaCO}_{3} \mathrm{e}$ MgO (RUSSELL et al., 1979); antibióticos ionóforos, como monensina, lasalocida; antibióticos não-ionóforos, como tilosina e virginamicina (RUSSELL et al., 1987); suplementos gordurosos (HEGARTY, 1999) e ácido málico (MARTIN, 1998).

\section{Conclusões}

Com a intensificação dos sistemas produtivos no Brasil, a cetose, a lipidose hepática, a acidose e o timpanismo vão se tornar cada vez mais freqüentes nos 
animais de alta produtividade. Os técnicos atuantes na área devem buscar alternativas nutricionais e terapêuticas viáveis para reduzir os efeitos drásticos que estas doenças promovem, comprometendo a sustentabilidade do sistema de produção.

É importante ressaltar que os ruminantes são herbívoros e necessitam de níveis mínimos de fibra tanto para manter o pleno funcionamento do trato gastrintestinal quanto para a produção (carne, leite). Os alimentos alternativos, principalmente os resíduos e co-produtos da agroindústria, podem ser utilizados para que estes níveis mínimos sejam atingidos, sem que haja prejuízos econômicos para os produtores.

Mais pesquisas são necessárias para que a influência do manejo nutricional, visando evitar distúrbios metabólicos, seja completamente entendida.

\section{Referências}

AROEIRA, L.J.M. 1998. Cetose e infiltração gordurosa no fígado em vacas leiteiras. EMBRAPA-CNPGL, Juiz de Fora.

BAILE, C. A.; McLAUGHLIN, C. L. 1978. Chemically stimulated feed intake in ruminants. Cereal Foods world, 23: 290-299.

BAUMAN, D.E. 1992. Bovine somatrotopin: rewiew of an emerging animal technology. Journal of Dairy Science. 75(11): 3432-3440.

BAVERA, G. A.; PEÑAFORT ,C. H.[s.n.t.]. Cursos de Producción Bovina de Carne. 2007. (Acesso em 11/08/2009). FAV UNRC. Disponível em $<$ http://www.produccionbovina.com>

BORGES, F.B. [s.n.t.]. $2003^{a}$. Uso de niacina na alimentação de vacas de alta produção. (Acesso em 11/08/2009). Disponível em: <zootec.com.br/niacina.htm>

BORGES, F.B. [s.n.t.]. Utilização de ionóforos e antibióticos na alimentação de bovinos. 2003b. (Acesso em 11/08/2009). Disponível em: $<$ www.zootec.com.br/ionoforo.htm>

BROWN, M. S., PONCE , C. H.; PULIKANTI, R. 2006. Adaptation of beef cattle to high-concentrate diets: performance and ruminal metabolism. Journal of Animal Science. 84(E. Suppl.): E25-E33. 
CONTI, R. M. C., SCHALCH, E., SALLES, M. S. V. 2002. Efeito da monensina na produção e composição do leite e parâmetros reprodutivos em vacas holandesas. In: REUNIÃO ANUAL DA SOCIEDADE BRASILEIRA DE ZOOTECNIA, 39, 2002, Recife. Anais... Recife:Gmosis, 2002, 17 par. CD-ROM. Nutrição de Ruminantes. NUR - 822.

CHENG, K.J, McALLISTER, T.A.; POPP, J.D.; HRISTOV, A.N.; MIR, Z.; SHIN, H.T. 1998. A review of bloat in feedlot cattle. Journal of Animal Science. 76(1): 299-308.

DUFFIELD, T.F.; LESLIE, K.E.; SANDALS, D.; LISSEMORE, K.; McBRIDE, B.W.; LUMSDEN, J.H.; DICK, P.; BAGG, R. 1999. Effect of prepartum administration of monensin in controlled-release capsule on milk production and milk components in early lactation. Journal of Dairy Science. 82(2): 1254-1263.

FLEMING, S.A. 1993. Cetose dos ruminantes (acetonemia). Págs.1297-1304, v.2, em: Smith, B.P (ed.), Tratado de Medicina Interna de Grandes Animais. Editora Manole, São Paulo.

FERREIRA, A.J.P.; DEL'PORTO, A. 1999. Agentes Antiprotozoários. Págs.466479 em: Spinosa, H.S.; Górniak, S.L.; Bernardi, M.M (eds.), Farmacologia Aplicada à Medicina Veterinária. Editora Guanabara - Koogan (2a ed.), Rio de Janeiro.

GEORGE, L.W. 1993. Moléstias do sistema nervoso: Tétano. Págs.1018-1021 em: Smith, B.P. Tratado de Medicina Interna de Grandes Animais. Editorial Manole,. São Paulo.

GONZÁLEZ, F.H.D.; CAMPOS, R. 2003. Indicadores metabólico-nutricionais do leite. Págs.31-47 em: González, F.H.D.; Campos, R (eds.). Simpósio de Patologia Clínica Veterinária da Região Sul do Brasil,1. Anais... Porto Alegre.

HEGARTY, D. C. 1999. Mechanism for competitively reducing ruminal methanogenesis. Australian Journal of Agriculture Research 50(8): 1299 - 1305.

HIRONAKA, R.; FREEZE, B. 1992. Feedlot finishing of cattle. Minister of Supply and Services, Otawa.

HOWARTH, R.E.; CHENG, K-J.; MAJK, W.; COSTERTON, J.W. 1986. Ruminant bloat. Pgs.516-527 In: Milligan, L.R; Grovum, W.L.; Dobson A (eds.),. Digestion and metabolism in ruminants. Prentice-Hall, New Jersey

HUTJENS, M.F. 1992. Selecting feed additives. Pgs.309-317 In: Van Horn, H.H.; WILCOX, C.J (eds.), Large dairy herd management. Savoy, USA.

JUCHEM, S.O.; SANTOS F.A.P.; PIRES, AV. 2000. Efeito da administração de propileno-glicol e monensina sódica pré-parto em vacas de alta produção: 1. 
Produção e composição do leite. Em: REUNIÃO ANUAL DA SOCIEDADE BRASILEIRA DE ZOOTECNIA, 37, Viçosa. Anais... Viçosa:Gmosis, 17 par. CDROM. Nutrição de Ruminantes. NUR - 1024.

MACHADO, P.F.; MADEIRA, H.M.F. 1990. Manipulação de nutrientes em nível de rúmen - Efeitos do uso de ionóforos. Págs.41-58 em: Machado.; P.F.; Madeira, H.M.F. Novas tecnologias de produção animal. FEALQ, Piracicaba.

MAJAK, W., HALL, J.W., MCCAUGHEY. 1995. Pasture management systems for reducing the risk of legume bloat in cattle. Journal of Animal Science. 73(5): 14931498.

MACLACHLAN, N.J., CULLEN, J.M. 1998. Fígado, Sistema Biliar e Pâncreas Exócrino. Págs.95-131 em Carlton, W.W., McGavin, M.D. Patologia Veterinária Especial de Thomson ( $2^{\mathrm{a}} \square \mathrm{d}$.). ARTMED, Porto Alegre.

MARTIN, S. A. 1998. Manipulation of ruminal fermentation with organic acids: a review. Journal of Animal Science.76(12): 3123-3132.

MILLEO, T.C.; HARTMANN, W.; HILL, J.A.G.; NETTO, U.G.; MAURER JUNIOR, F.R. 2006. Alterações clínicas e laboratoriais em bovinos em quadro de acidose lática ruminal. Em: Seminário de Iniciação Científica da Universidade Tuiuti do Paraná, 5, 2006. Curitiba. Anais... Seminário de Iniciação Científica da Universidade Tuiuti do Paraná.

NAGARAJA, T.G. 2007a. Saúde do Rúmen. Págs.1-4 em: Arrigoni, M.; Martins; C.I.; Millen, D.D.; Laurianto Pacheco, R.D. (eds.), Simpósio de Nutrição de Ruminantes. Anais... FMVZ/UNESP, Botucatu.

NAGARAJA, T.G . 2007b. Manipulação do Rúmen para Minimizar Problemas. Págs.132-145 em: Arrigoni, M.; Martins; C.I.; Millen, D.D.; Laurianto Pacheco, R.D. (eds.), Simpósio de Nutrição de Ruminantes. Anais... FMVZ/UNESP, Botucatu.

ORTOLANI, E.L. 2003. Diagnóstico e tratamento de alterações ácido-básicas em ruminantes. Págs.17-29 em: GONZÁLEZ, F.H.D.; CAMPOS, R (eds.), Simpósio de Patologia Clínica Veterinária da Região Sul do Brasil. 1. Anais... Gráfica da Universidade Federal do Rio Grande do Sul, Porto Alegre.

OWENS, F.N.; SECRIST, D.S.; HILL, W.J.; GILL, D.R. 1998. Acidosis in cattle: a review. Journal of Animal Science. 76(1):275-286.

PEARSON, E.G., MAAS, J. 1993. Lipidose Hepática. Págs.861-867 em: Smith, B.P. (ed.), Tratado de Medicina Interna de Grandes Animais. v.1. Editora Manole, São Paulo. 
PEREIRA, J.R.A.; SANTOS, I.R.; COUTO, H.T. 2001. Efeito da monensina sódica sobre a produção e composição do leite. Em: REUNIÃO ANUAL DA SOCIEDADE BRASILEIRA DE ZOOTECNIA, 38, 2001, Piracicaba. Anais... São Paulo:Gmosis, 2001, 17 par. CD-ROM. Nutrição de Ruminantes. NUR - 0708.

RUCKEBUSH Y.; OOMS, L.A.; DEGRYSE, A.D.; ALLAL, C. 1985. Alleviation of excessive gas accumulation in the ruminant stomach by ritanserin. American Journal of Veterinary Research 46(2):434-437.

RUSSELL, J.B.; SHARP, W.M.; BALDWIN, R.L. 1979. The effect of pH on maximum bacterial growth rate and its possible role as a determinant of bacterial competition in the rumen. Journal of Animal Science 48(2):251-258.

RUSSELL, J.B. A proposed mechanism of monensin action in inhibiting ruminal bacterial growth: effects on ion flux and protonmotive force. Journal of Animal Science 64(5): 1519-1525.

SANTOS, J.E.P. 2006. Distúrbios metabólicos. Págs.423-492 em: Nutrição de Ruminantes. BERCHIELLI, T.T. (ed.), Nutrição de Ruminantes. FUNEP, Jaboticabal.

SEGLAR, W. 1997. Maximizing forage quality. Pioneer Hi-Bred International, Johnston.

SPRINKLE, J.E. 1999. Feeding management for show lambs. University of Arizona Cooperative Extension Publication \#AZ1053 (Acesso em 12/09/2009). Disponível em: <http://cals.arizona.edu/ pubs/animal/az1053.pdf>.

STAPLES, C. R.; THATCHER, W. W.; MATTOS, R. 2001. Estratégia de suplementação de gordura em dietas de vacas em lactação. Págs.298-330 em: SIMPÓSIO INTERNACIONAL DE BOVINOCULTURA DE LEITE, 2001, Anais...UFLA, Lavras.

STOCK, R. A.; BRINK, D. R.; BRANDT, R. T.; MERRIL, J.K.; SMITH, K.K. 1987. Feeding combination of high moisture corn and dry corn to finishing cattle. Journal of Animal Science 65(1): 282-289.

TEIXEIRA, J. C. 1997. Alimentação de bovinos leiteiros. FAEPE, Lavras.

VOGEL, G. J.; PARROT, J. C. 1994. Mortality survey in feedyards: the incidence of death from digestive, respiratory, and other causes in feedyards on the Great Plains. The Compendium on continuing education for the Practice Veterinary 16(2):227-234.

WITTWER, F. 1996. Diagnóstico de desbalances de energía y proteínas mediante el análisis de muestras de leche y su impacto productivo en rebaños lecheros. 
Págs.71-84 em: Lanuza, G.; Bortolomeolli, G (ed.), Seminario: Aspectos técnicos y perspectivas de la producción de leche. 3. Ed. F., Serie Remehue 6

WITTWER, F. 2000. Marcadores bioquímicos no controle de problemas metabólicos nutricionais em gado de leite. Págs.53-62 em: González, F.H.D.; Barcellos, J.O.; Ospina, H (eds.), Perfil metabólico em ruminantes: seu uso em nutrição e doenças nutricionais. UFRGS, Porto Alegre.

WOLFF, J.; BRYAN, A.M.; CORDES, D.O.; RAMBERG, C.F. 1978. Can a metabolic profile be developed for New Zealand condition. New Zeland Veterinary Journal 26(11):266-269.

ZINN, R. A., A. PLASCENCIA, R. BARAJAS. 1994. Interaction of forage level and monensin in diets for feedlot cattle on growth performance and digestive function. Journal of Animal Science 72(9):2209. 